\title{
Desafios do ensino de matemática com tecnologias digitais nos anos iniciais
}

\author{
Challenges of teaching Mathematics with digital technologies in the \\ early years
}

\section{Los desafíos de la enseñanza de las Matemáticas con tecnologías digitales en los primeros años}

\author{
Elisângela Soares Ribeiro' \\ Departamento de Vigilância Sanitária, Servidora Pública. \\ https://orcid.org/0000-0002-3785-2608 \\ Irani Parolin Sant'Ana ${ }^{2}$ \\ Universidade Estadual do Sudoeste da Bahia, Professora. \\ http://orcid.org/0000-0002-1857-3638 \\ Claudinei de Camargo Sant'Ana ${ }^{3}$ \\ Universidade Estadual do Sudoeste da Bahia, Professor titular. \\ http://orcid.org/0000-0003-1429-4559
}

\begin{abstract}
Resumo: Esta artigo é um recorte da pesquisa de mestrado que possui como objetivo principal identificar e analisar as possibilidades, desafios em utilizar pedagogicamente as tecnologias na formação continuada de professores que ensinam Matemática nos anos iniciais. Foi realizado um curso de extensão semipresencial em 2016 para professores dos anos iniciais da Educação Básica. Como parte do desenvolvimento da pesquisa nos valemos do Fórum de Discussão do Facebook (FDF) e o Diário dos participantes que foi produzido no Google DOC (DB). Os dados foram analisados utilizando a Análise Textual Discursiva (ATD) e os resultados apontam que os professores reconhecem que as Tecnologias Digitais (TD) estão cada vez mais próximas da vida escolar bem como a importância da formação continuada para alavancar a utilização das TD em sala de aula.
\end{abstract}

Palavras-chave: Formação Docente. Desafios. Tecnologias.

Mestre em Educação Científica e Formação de Professores pela Universidade Estadual do Sudoeste da Bahia; Especialista em Gestão em Saúde pela Fundação Oswaldo Cruz.

2 Doutora em Educação Matemática pela Universidade Anhanguera de São Paulo; Mestre em Ensino, Filosofia e História das Ciências pela Universidade Federal da Bahia e pela Universidade Estadual de Feira de Santana.

3 Doutor em Educação pela Universidade Estadual de Campinas; Mestre em Engenharia Mecânica pela Universidade Estadual de Campinas. 
Abstract: This article is a cutout of the master's research that has as its main objective to identify and analyze the possibilities, challenges in pedagogically using the technologies in the continuing education of teachers who teach Mathematics in the initial years. A semi-presential extension course was held in 2016 for teachers in the initial years of Basic Education. As part of the development of the research we used the Facebook Discussion Forum (FDF) and the Participants' Journal which was produced in Google DOC (DB). The data were analyzed using Discourse Textual Analysis (ATD) and the results show that teachers recognize that Digital Technologies (DT) are increasingly closer to school life as well as the importance of continuing education to leverage the use of DT in the classroom.

Keywords: Teaching Formation. Challenges. Technologies.

Resumen: Este artículo es un recorte de la investigación del máster que tiene como objetivo principal identificar y analizar las posibilidades, retos en el uso pedagógico de las tecnologías en la formación continua de los profesores que enseñan matemáticas en los primeros años. En 2016 se realizó un curso de extensión semipresencial para profesores de los primeros años de la Educación Básica. Como parte del desarrollo de la investigación se utilizó el Foro de Discusión de Facebook (FDF) y el Diario de los Participantes que se produjo en Google DOC (DB). Los datos fueron analizados utilizando el Análisis Textual del Discurso (ATD) y los resultados muestran que los profesores reconocen que las Tecnologías Digitales (DT) están cada vez más cerca de la vida escolar, así como la importancia de la educación continua para aprovechar el uso de la DT en el aula.

Palabras-clave: Formación Docente. Desafios. Tecnologías.

Recebido em 27 de janeiro de 2020 Aceito em 1 de maio de 2020

\section{INTRODUÇÃO}

No início do século XXI ocorreram diversas inovações tecnológicas que interferiram definitivamente na vida humana, assim Lèvy preconizava as relações da internet:

\footnotetext{
Uma imensa rede loucamente complicada, que pensa de forma múltipla, cada nó da qual é por sua vez um entrelace indiscernivel de partes heterogêneas, e assim por diante em uma descida fractal sem fim. Os atores desta rede não param de traduzir, de repetir, de cortar, de flexionar em todos os sentidos aquilo que recebem de outros. Pequenas chamas evanescentes de subjetividades intrapessoais do gesto, do olhar, da carícia. (LÉVY, 1993, p. 175).
} 
De certo que hoje vivemos o que foi preconizado, com múltiplas implicações da rede nacional, assim 0kada (2003) a interpreta como sendo complexa e subjetiva, onde existem pluralidade de caminhos para o desenvolvimento da inteligência artificial de autoria coletiva.

Tais avanços possibilitam a utilização de diversos serviços oriundos da convergência de mídias que em muito propiciam a facilitação da socialização de serviços, produtos e a disseminação de informações em espaços desterritorializados (LÉVY, 1993).

As mudanças ás quais está submetida toda a nossa sociedade, o papel do docente na implementação de alterações e inovações na educação é inevitável, principalmente na utilização pedagógica das tecnologias no ensino de Matemática, observado em pesquisas como as desenvolvidas por Cannone, Robayna e Medina (2008); Sant'Ana, Amaral e Borba (2012), Sousa e Sant'Ana (2017), Brito e Sant'Ana (2020); Brito, Sant'Ana e Sant'Ana (2020).

Um dos determinantes para a utilização das Tecnologias de Informação e Comunicação (TIC) é o entendimento de que as mesmas podem favorecer:

[...] a dinamização e ampliação das habilidades cognitivas, devido à riqueza de objetos e sujeitos com os quais permitem interagir; a possibilidade de extensão da memória e de atuação em rede; ocorre a democratização de espaços e ferramentas, pois estas facilitam o compartilhamento de saberes, a vivência colaborativa, a autoria, co-autoria, edição e a publicação de informaç̃̃es, mensagens, obras e produç̃̃es culturais tanto de docentes como discentes. (SERAFIM; SOUSA, 2011, p. 22).

Vivemos momento ímpar, onde muitos valores e costumes estão sendo questionados e modificados, via de regra, a titulação já não garante o conhecimento e colocação profissional:

0 que era uma virtude e um indicativo de competência e garantia de sobrevivência trazidos pelo diploma, no capitalismo flexivel perde sua validade absoluta. 0 tempo de exercício deixa de ser critério único para qualquer análise do trabalho e de seu papel na vida de quem trabalha. (CECÍLO; ARAÚJO, 2013, p. 351).

Certamente obervamos que somente a titulação não garante o desenvolvimento adequado de qualquer profissão e obviamente isso é válido para os professores, que devem participar da construção do conhecimento dos estudantes. No contexto atual o professor teve suas funções reconfiguradas e não pode mais ser "[...] tido como 'transmissor de conhecimentos', aquele que 'ensina a matéria'." Outros conteúdos se somam aos mais tradicionais e indicam uma multidimensionalidade de unidades e de sentido que permeiam 
definindo o papel da docência e do trabalho docente (CECíL10; ARAÚJ0, 2013, p. 353), existindo uma gama de conhecimentos e atitudes que vão sendo acrescidos e modificados à docência.

Retomamos o fato de que retratamos aqui um recorte da pesquisa de mestrado ${ }^{4}$ da primeira autora deste artigo Ribeiro (2017), onde se buscou a aproximação entre a Escola Básica e a Universidade via formação continuada de professores, utilizamos aqui também as fontes apresentadas na pesquisa de Ribeiro (2017), para responder à questão de pesquisa: Quais os desafios enfrentados pelo professor em utilizar tecnologias para o ensino da Matemática nos anos iniciais?

\section{PROCEDIMENTOS METODOLÓGICOS}

Foram utilizados como Ambientes Virtuais de Aprendizagem (AVA) o Facebook ${ }^{5}$, onde ocorreram discussões de artigos relacionadas com a formação de professores, Ensino de Matemática e a utilização das TIC; o Google $D o c^{6}$ que foi um facilitador para construção do diário de bordo onde foi relatado o desenvolvimento de todo o processo e finalmente o software de Autoria Visual Class ${ }^{7}$ que utilizamos para construção das atividades focadas para o $2^{\circ}$ e $3^{\circ}$ ano do Ensino Fundamental l. Os participantes da pesquisa foram quatro professores de uma escola pública, que para preservarmos a identidade dos mesmos, passaremos a identificá-los como PI, P5, P8 e P9 e foram escolhidos por chegarem ao final do curso de extensão com todas as atividades realizadas. Seguem as informações sobre os participantes na Tabela 1:

Tabela1 - Características gerais das docentes participantes da pesquisa

\begin{tabular}{lrrrrrr}
\hline Docentes & Idade & $\begin{array}{c}\text { Formação } \\
\text { Acadêmica }\end{array}$ & $\begin{array}{c}\text { Ano da } \\
\text { Formação }\end{array}$ & $\begin{array}{c}\text { Tempo de } \\
\text { Docência }\end{array}$ & $\begin{array}{c}\text { Ano que } \\
\text { leciona }\end{array}$ & $\begin{array}{c}\text { Horas de trabalho } \\
\text { semanal }\end{array}$ \\
\hline PI & 35 & Pedagogia & 2008 & 4 anos & $2^{\circ}, 3^{\circ}, 4^{\circ}$ e $5^{\circ}$ & 40 \\
P5 & 27 & Pedagogia & 2014 & 2 anos & $2^{\circ}$ & 40 \\
P8 & 47 & Pedagogia & 2015 & 13 anos & $3^{\circ}$ & 40 \\
P9 & 35 & Pedagogia & 2015 & 12 anos & $2^{\circ}$ & 40 \\
\hline
\end{tabular}

Fonte: Ribeiro (2017).

Os dados analisados dizem respeito à um curso de extensão semipresencial de 180 horas, realizado entre julho e setembro de 2016, organizado no âmbito do Programa de

\footnotetext{
4 A pesquisa foi aprovada pelo Comitê de Ética e Pesquisa (CEP), com parecer de número: 1.138201.

5 https://www.facebook.com/

6 https://www.google.com/int//fr/docs/about/

7 http://www.classinformatica.com.br/
} 
Extensão Atividades Colaborativas e Cooperativas em Educação (ACCE), vinculado ao Grupo de Estudos em Educação Matemática (GEEM) ${ }^{8}$, no desenvolvimento utilizamos a Pesquisa Formação, enquanto espaço de construção de trabalho coletivo, proporcionando benefícios para o pesquisador e pesquisados (LONGAREZI; SILVA, 2013).

Executaremos neste texto a análise da produção reflexiva dos professores nos encontros presenciais, no Diário de Bordo dos professores registrados no Google Doc e os Fóruns de Discussão no Facebook. No que se refere à análise dos dados, foi utilizada a Análise Textual Discursiva (ATD) na intenção de conseguirmos interpretá-los de maneira adequada dando significado aos processos formativos (MORAES; GALIAZZI, 2011).

\section{OS DESAFIOS DO PROFESSOR QUE UTILIZAM TECNOLOGIAS PARA ENSINAR A MATEMÁTICA NOS ANOS INICIAIS}

Investigações sobre a profissão docentes são registrados desde os últimos anos do século XX em países como Inglaterra, Estados Unidos, Canadá, França, Bélgica, Suíça e Brasil, identificando desafios no desempenho da prática docente (TARDIF; LESSARD, 2013).

A evolução das melhorias tecnológicas nem sempre chegam até a escola ou até a sala de aula, a docência ainda enfrenta dificuldades diversas para adquirir novos conhecimentos para a utilização de novos anteparos tecnológicos. Diversos são os desafios para ensinar no contexto de um mundo globalizado e permeado pelas tecnologias (RAMALHO; NUÑEZ; GAUTHIER, 2004).

Os percalços da carreira docente, aliados à falta de formação continuada constituem-se em grandes empecilhos para implementação das TD na sala de aula. Purificação, Neves e Brito (2010) destacam alguns que são fonte de problemas diversos para o professor, por exemplo a insegurança, falta de preparação, falta de experiência, e etc, para implementação das TD em sala de aula.

Cirino e Souza (2009, p. 5) apontam que "No mundo dos computadores, da Internet e do universo multimídia o professor é chamado à mudança, vendo-se obrigado a repensar a sua profissão, as estratégias que utiliza e a lutar pela melhoria das práticas educativas." “Esse tipo de processo formativo inclui percepções e análise crítica do papel profissional do professor, visando à ruptura com ideologias impostas, com o conformismo, com a inércia e a alienação profissional." (COSTA, 2010, p. 89). Em tal perspectiva, os professores mais uma

\footnotetext{
8 http://geem.mat.br
} 
vez são convidados a colaborarem e dispender esforços para acompanhar a mudança que definitivamente chegaram à escola. , seja pela via dos mestres ou nos bolsos dos estudantes.

A implementação de mudanças pedagógicas que envolvam a inclusão das tecnologias demandam tempo, investimento e desenvolvimento de habilidades que vão muito além da utilização particular, pois trata-se da utilização em ações de ensino, em sala de aula. Pesquisas como as desenvolvidas por Ribeiro, Santana e Sant'Ana (2018), Borba, Silva e Gadanidis (2014), Sant'Ana, Amaral e Borba (2012), Purificação, Neves e Brito (2010), Costa (2010) e Cannone, Robayna e Medina (2008) ressaltam a importância da utilização das TD em sala de aula e, claro, também os desafios desta implementação.

Dois deles são recorrentes: a desistências dos processos formativos em andamento e o desestímulos no uso das TD por desconhecimento da possibilidade de utilização pedagógicas. Ainda, a possibilidade inerente de durante o processo de ensino passar de avaliador para avaliado pelos próprios estudantes (COSTA, 2010). Assim, acreditamos haver necessidade de unir o ensino de Matemática e as TD "[...] promover a aproximação e a interação dos fatos da realidade com o conteúdo [...]" (ALMEIDA; SILVA; VERTUAN, 2012, p. 32), visto que as tecnologias estão cada vez presentes em nossa sociedade e podem colaborar com a contextualização, cooperação, e desenvolvimento do processo educativo.

Nas linhas seguintes iremos discutir os resultados provenientes da formação continuada, utilizando as reflexões dos professores e também as perspectivas de utilização do software Visual Class.

\section{ANÁLISE DOS DADOS}

Os professores que procuram utilizar as TD na educação enfrentam situações que os remetem à uma zona de conforto ou de risco (ALMEIDA; SILVA; VERTUAN, 2012), não é diferente para o pedagogo ao trabalhar com o Ensino de Matemática e as TD.

Como material de análise, foram produzidos planos de aula relacionando o Ensino de Matemática e as TD, representado no Quadro 1 a seguir:

Quadro 1 - Eixos e Conteúdos

\begin{tabular}{|l|l|l|l|l|}
\hline Eixo temático & \multicolumn{1}{|c|}{$\begin{array}{c}\text { Grandezas e } \\
\text { Medidas }\end{array}$} & $\begin{array}{c}\text { Números e } \\
\text { Operações }\end{array}$ & \multicolumn{1}{|c|}{ Espaço e Formas } & Números e Operações \\
\hline Conteúdo & $\begin{array}{l}\text { Medidas de tempo } \\
\text { e hora }\end{array}$ & Subtração & $\begin{array}{l}\text { Figuras Geométricas } \\
\text { planas e não planas }\end{array}$ & $\begin{array}{l}\text { Números no contexto } \\
\text { diário }\end{array}$ \\
\hline
\end{tabular}

Fonte: Ribeiro (2017). 
Na produção das atividades relacionadas com as TD e o ensino de Matemática os professores tiveram liberdade na criação Ribeiro, Santana, Sant'Ana (2018). Identificamos desafios variados no esforço de produção das atividades por parte dos professores para o ensino de Matemática nos anos iniciais, conforme passaremos a informar e discutir:

[...] uma alfabetização também, engraçado quando a gente pensa em alfabetização, a gente pensa na leitura e escrita, tá incumbido leitura e escrita. Mas também existe a alfabetização Matemática que é um dos pontos importantíssimo para a criança aprender a questão numérica, e é tão difícil quanto ler e escrever, porque tem crianças que não conseguem identificar os números, até crianças maiores, de séries maiores [...] (P9, DB) (informação verbal).

É notório também, para além da preocupação com o Ensino de Matemática, a necessidade de estar minimamente preparado para desenvolver tal atividade, vejamos:

Olha só!!! A questão de preparação não digo que a gente sempre tá preparada para tudo, a gente tá o tempo todo em processo de aprendizado. As vezes até com o aluno, você começa a discutir, refletir sobre determinadas coisas relacionadas a todas as disciplinas, relacionada a Matemática também, então quando a gente fala: está preparado, acredito que não esteja, a gente nunca tá preparado pelo menos eu, nunca digo que estou preparada. (P9, DB) (informação verbal).

Notadamente, fica à cargo dos professores a responsabilidade de desenvolvimento profissional, incluindo aqui o aperfeiçoamento e aquisição de novos conhecimentos que podem promover também novas práticas.

\subsection{DIFICULDADE DE ADAPTAÇÃO DO PROFESSOR À CULTURA DIGITAL: O MEDO DE ERRAR}

Para o uso das tecnologias na formação de professores de Matemática dos anos iniciais, ainda persiste a dicotomia da inovação e do receio de implementação Purificação, Neves e Brito (2010). Podemos conjecturar que tal sentimento extrapola o que encontramos em nossa pesquisa, conforme observamos na declaração de duas cursistas no que se refere à utilziacao do software de autoria Visual Class: 
No dia que era para criar o projeto, eu falei: Aí meu Deus, será que é verdade, que vou criar esse projeto no Visual? Como que vai ser? A pesquisadora mostrou aquele projeto que fez, mas eu vou criar? Ficava assim aquele medo. Quando chegou aqui, ela falava, dava informação, mas parece que eu não captava, aí ela perguntava: Você fez assim? Eu estava para poder dizer: - Não vou fazer mais nada. (PI, REP).

Os desafios são inúmeros neste processo de aprendizagem. 0 medo de não conseguir, o receio de errar, a insegurança na realização do projeto, do mesmo fugir do planejamento inicial, enfim. (P9, DB) (informações verbais).

A insegurança gerada pela possibilidade de incorrer em equívocos, ocasionou o impedimento de adquirir habilidades para colocar em prática o plano de aula, consequentemente desaguando em preocupação e medo, conforme pudemos observar no relato anterior de $\mathrm{Pl}$.

Naturalmente entendemos a mudança, a chegada do novo tecnológico, como algo que pode ser motivador, no entanto, a novidade pode vir acompanhada da preocupação e insegurança do desenvolvimento pedagógico da prática profissional Souto (2014). Observe que P9 e Pl apresentam a insegurança de poder aprender a utilização das TD pedagogicamente, bem como que esta pudesse afastá-las do planejamento original escolar.

Apesar da insegurança das professoras em trabalharem com as tecnologias, ambas admitiram a importância de construírem o conhecimento e incorporarem em suas práticas, tais mudanças dependem de tentativas: "Hoje por exemplo me senti frustrada quando pensei ter conseguido fazer três atividades e no final percebi que havia salvado errado, me senti um pouco incapaz e não senti vontade de mexer no programa em casa, talvez por medo de errar." (P8, DB) (informação verbal).

A professora P8 manifestou a sua insatisfação referente aos primeiros contatos com o software Visual Class. Esse sentimento se deu pois na construção do projeto em vez de trabalhar o planejamento em uma tela, construiu dois projetos concomitantes, isso acabou gerando uma sensação de incapacidade, ansiedade, e sensação de estar errando na exploração da tecnologia.

As práticas pedagógicas devem acompanhar o ritmo frenético em que as informações evoluem. PI e P9 compreendem a necessidade de mudanças, porém em seu relato demonstram resistência em aderir ao novo, "Outra coisa que estava pensando que nós educadores atuais, a gente fica com um pé no passado e outro no futuro, querendo se adequar as novidades, as tecnologias, mas não consegue aderir a essas novidades por $n$ questões [...]" (PI, REP) (informação verbal). 
Em relação a utilização rotineira do material didático e a apresentação de conteúdos pelas tecnologias, relata $\mathrm{P9}$ :

\begin{abstract}
[...] hoje o livro didático está muito rico, voltado para a atualidade, para questões concretas, e quando a gente para e analisa o livro lá no finalzinho, no manual do professor, você vai ver que aquele conteúdo que trabalhou tem links voltados para as tecnologias, vem vídeos voltados para o conteúdo que você quer, então de certa forma também já existe esse tipo de trabalho, só que a gente por insegurança, por não querer fazer, por ter muita coisa, acaba fugindo disso [...] (P9, REP) (informação verbal).
\end{abstract}

A chegada e as "exigências" da tecnologia no meio educacional são implacáveis, não espera somente demanda, não se pode ficar na zona de segurança do passado, no presente o futuro espreita com a emergência da atualização e do aprendizado que as TD trazem.

\title{
4.2 A FALTA DE MATERIAIS TECNOLÓGICOS E DA ESTRUTURA FÍSICA ADEQUADA
}

A utilziacao das TD em sala de aula demandam que as mesmas também estejam disponiveis na escola, que o professor tenha acesso e franquiada em número e qualidade para todos os docentes, conforme P5 "[...] às vezes a gente planeja e tenta trazer o celular. Eles tentam mexer, mas o que a gente quer da parte pedagógica não contempla, porque só a televisão não vai dar conta." (P5, REP) (informação verbal).

Evidentemente que, ainda que existam equipamentos nas escolas, é fundamental que sejam aqueles que os professores entendem que possam trazer ganhos para 0 desenvolvimento de suas atividades, conforme apontam P8, P5 e P9:

[...] há que se fazer investimentos materiais e na capacitação de professores, cada um deve fazer a sua parte para que a mudança ocorra de fato e que a qualidade no ensino evolua junto com a tecnologia. (P8, FDF).

[...] professores e alunos se deparam com a falta de estrutura, com as dificuldades de utilizarem o Laboratório de Informática por conta do sucateamento, da falta de manutenção [...] (P5, FDF). 


\begin{abstract}
Mas enxergamos também a nossa estrutura - ou a falta dela - que não contribui para a vivência plena dessa realidade que se apresenta para nós. (P5, DB).

Na nossa prática somos o tempo todo desafiados, [...], desafiados com a estrutura da escola, desafiados num contexto geral [...] Eu espero que no próximo encontro eu não fique desprovida de computador funcionando e que possamos realizar este trabalho de maneira mais efetiva [...] (P9, REP) (informações verbais).
\end{abstract}

De todo modo, mesmo a escola possuindo laboratórios, raramente estão em condições de utilização os problemas se amontoam, assim como as máquinas nos laboratórios.

\title{
4.3 A FALTA DE FORMAÇÃO TEÓRICA E PRÁTICA EM TECNOLOGIAS
}

Entendemos que o novo modelo possível de educação que envolva as TD implica também na preparação dos profissionais para tal, Purificação, Neves e Brito (2010), pois estes são impactados pelas pressões que chegam até a escola, havendo um confronto do cohecimento que possuem frete ao dos estudantes.

Para Pl, “É importante e já foi falado aqui da importância da formação. Cadê esse professor preparado para trabalhar com essa realidade, com essa necessidade atuale?" (PI, REP) (informação verbal), a formação é algo notório e importante para os professores, bem como a instrumentação das escolas, como destacam Serafim e Sousa (2011).

A situação defasada da utilização de recursos tenológicos propricia também o empecilho da utilização na vida particular. Como podemos observar, à respeito do Editor de Texto e programas para Apresentação P9 (REP) diz: “.... quando a gente pega o computador, a gente utiliza para o Facebook, internet. 0 Word? Sabe mexer? Às vezes a gente tem dificuldade para centralizar um texto, mexer no Word, ir ao Power Point fazer um slide. Então, acho que os conhecimentos básicos são precisos." (informação verbal).

Com os resultados que fomos obtendo, acreditamos existir a necessidade de formação básica para os professores na utilização das tecnologias, ainda que para a utilização particular e posteriormente avançar para o contexto pedagógico. 


\subsection{A SOBRECARGA DE TRABALHO QUE REFLETE NA FALTA DE TEMPO PARA APRENDER}

Aparentemente existe uma interligação entre os obstáculos para se utilizar as TD em sala de aula, na medida exata em que existe uma carga de trabalho adequada, o profissional não dispõe de tempo para realizar processos formativos que, devem impactar positivamente em sua prática pedagógica, conforme podemos observar à seguir:

[... até você lidar e saber usar essas informações demanda tempo, [... [...]
você tem que ter tempo para ir praticando, porque tudo vai da prática, não
adianta a gente aprender aqui e depois de dois a três meses ir ver se
consegue, tem que ir praticando, ir mexendo, e ir descobrindo os comandos
[...] (P9, REP).

[...] é possivel observar que o educador tem uma série de desafios como: encontrar tempo para se adequar às novas exigências as quais a educação contemporânea traz, e estar participando de cursos de formação continuada, inovando sua prática pedagógica, inserindo as novas tecnologias para que se obtenham melhores resultados no processo de ensino aprendizagem. (PI, DB).

[...] o educador não se sente preparado para utilizar as ferramentas, e isso muda toda a rotina do professor, que tem que se capacitar, se preparar, demanda tempo, esforço, disponibilidade de curso. (PI, REP) linformações verbais).

Ao observermos a declaração de PI fica claro que a mesma aponta a necessidade de planejamento e formação, que demandam tempo, o que a impede de estar devidamente preparada. Além dos argumentos apresentados, ela registra a falta de cursos específicos de formação para a utilização das TD pedagogicamente.

Quando existe a sobrecarga das atividades do professor é natural o surgimento de indisponibilidade para aprender novidades Purificação, Neves e Brito (2010); de certo que a integração das práticas educacionais com as TD necessita de um processo de apropriação específico. 


\subsection{A DIFICULDADE DE UISUALIZAR AS TECNOLOGIAS COMO RECURSO PEDAGÓGICO À MUDANÇA DE PRÁTICAS}

Em sua prática na Educação Básica, o profissional deve vivenciar momentos de aprendizagens para utilização das TD e que sejam tratadas como integrantes da rotina da escola, Serafim e Sousa (2011).

Talvez pela novidade, identificamos que os professores não vislumbram a aplicação direta das TD, talvez pela ausência da internalização das possibilidades e do próprio manuseio do recurso, Costa (2010).

Tais aspectos foram apresentados pelos professores, inicialmente no que diz respeito à utilização do Software de Autoria Visual Class conforme podemos observar:

\footnotetext{
[...] mais uma vez estamos sendo colocados em prova, é em relação a aprender a mexer com o software, não importa se você sabe muito, se você sabe pouco, ou não sabe nada [...] (P9, REP).

0 desafio do professor é trabalhar com a tecnologia por meio de um software educativo, empregando uma metodologia didática para desenvolver um conteúdo significativo no ensino da Matemática. (P9, DB).

Acho que é um desafio, mais um desafio a gente está pensando nessa tecnologia para a educação [...] (P5, REP) linformações verbais).
}

Ao observarmos a declaração de P9 podemos ver que ela se sente testada, visto que ao utilizar o software é necessário entender as potencialidades dos recursos disponiveis. Este processo conduz compreender a lógica e recursos específicos, integrá-los ao planejamento e executar incluindo as TD na sala de aula, Costa (2010) ou ainda "Não basta apenas colocar à disposição uma série de ferramentas; é necessário que haja interesses compartilhados, intimidade, perenidade nas relações." (LEMOS; LÉVY, 2010, p. 103).

Por outro lado, para P5 o desafio maior é a utilização pedagógica do software, visto que exige entendimento aprofundado dos recursos para compatibilizá-los à utilização pedagógica "A gente usa o Facebook para se comunicar, mas a gente não consegue ver essa ferramenta na sala. A gente já está tão acostumada a usar o Facebook só para isso que não consegue ver como uma ferramenta dentro da sala de aula." (P5, REP) (informação verbal). 


\subsection{OS NATIUOS DIGITAIS NA ESCOLA: E AGORA?}

Outro fator complicador para os professores, é a presença dos nativos digitais, pois "[...] o lugar social da criança na relação com as tecnologias digitais é marcado pela existência de uma 'expertise' garantida por uma 'experiência geracional inata' (criança-nativos) em contraposição às demais gerações (docentes-imigrantes)." (LOUREIRO; GRIMM; LUNARDI MENDES, 2016, p. 725).

Esta situação é de fácil observação, visto que o perfil das crianças e consequentemente dos estudantes nos últimos anos segue tão atualizado quanto as tecnologias. Para Prensky (2001), eles utilizam computadores, e smartphones em suas vidas cotidianas, imersos desde o nascimento neste mundo tecnológico (NOVIKOFF; PEREIRA, 2013). Em alguns momentos os professores indicam as falhas na formação neste aspecto "Sou semianalfabeta digital, mas reconheço a necessidade dos alunos que hoje eles não se contentam mais com a mesmice, [..] Então eu sinto essa necessidade de aprender mais para utilizar melhor as tecnologias." (P8, REP) (informação verbal).

As professores reconhem todas as demandas necessárias para implementação das TD em sala de aula, assim como sabem da importância de sua utilização:

É sabido da importância das TD, da dinamicidade, da facilidade que os educandos têm em aprender [...] (P5, DB).

0 professor, muitas vezes, sente-se despreparado para lidar com esse tipo de aluno e com determinadas situações que envolva tecnologias. A partir desse princípio, faz-se necessário que haja uma relação de parceria e troca com esses nativos digitais, um aprendizado mútuo. (P9, FDF).

Percebe-se que os alunos não são passivos e dispostos simplesmente a aprender o conteúdo, eles querem construir esse conhecimento, dar opinião, compartilhar e participar da aula. Porém, a maioria dos professores ainda não estão preparados para esses alunos, ainda se reproduz a escola da infância. (P8, FDF) (informações verbais).

Ao observarmos o relato anterior de $\mathrm{P9}$, ao mesmo tempo que reconhece a presença dos nativos digitais, aponta que sem ajuda não se consegue vencer os problemas enfrentados.

Esta situação indica também que o professor neste contexto, assume um novo papel, diferente daquele de detentor de todo o saber, é o que P9 deixa transparecer a oportunidade de aprendizado mútuo, entre professores e estudantes, Serafim e Sousa (2011). 
Esta interlocução fica claro no que informa P8, com a disponibilidade e vontade de interagir e utilizar as TD, o que necessariamente demanda novas posturas do professor. Em se tratando das dificuldades PI apresenta:

\begin{abstract}
Porém, o ensino com uso de recursos variados esbarra no problema que está na formação inicial do professor. Este profissional, muitas vezes tem a sua prática baseada naquilo que aprendeu enquanto estudante das séries iniciais, sua forma de ensinar tem como base o exemplo do professor de décadas atrás, ou então vai tentando aprender sozinho como se trabalhar os conteúdos, pois em sua formação inicial, durante a graduação não teve a oportunidade de aprender a usar as tecnologias no seu ensino, isso porque o professor da graduação também não sabe como utilizar esse recurso, o que é possivel perceber que nem mesmo as instituições de ensino superior estão totalmente preparadas para atender à demanda da sociedade contemporânea e ensinar os professores em formação a usarem a tecnologia no seu fazer pedagógico. (PI, FDF) (informação verbal).
\end{abstract}

Pl constrói um reflexão à cerca da utilização das tecnologias que, precisam ser entendidas pelos professores para serem também valorizadas e utilziadas, Serafim e Sousa (2011).

A velocidade na resolução de situações problemas e adaptações são características do mundo tecnológico, principalmente dos seus nativos, e isso é uma demanda da atualidade:

\footnotetext{
Os nativos digitais já nascem nesse mundo tecnológico com acesso rápido a jogos, espaços interativos onde tem contato com universos, cultura e lingua diferente. [...] por isso, um dos desafios do professor na atualidade é tornar a sala de aula um espaço mais interessante, um lugar onde o aluno deseje estar. (P8, FDF) (informação verbal).
}

Como indica P8, o ambiente dos nativos digitais é fundamentado na interatividade, consequentemente na construção de experiencias de vida, Prensky (2001).

Foram apresentados e discutidos vários posicionamentos das professoras no que se refere à utilização das TD em sala de aula, mas compete aqui ressaltar o que nos diz P9 "No entanto, os desafios surgiram para nos encorajar a superar os limites e mudar nossas práxis." (P9, DB) (informação verbal). 


\section{CONSIDERAÇÕES}

Neste artigo analisamos os desafios da utilização das tecnologias na formação continuada de professores no ensino de Matemática nos anos iniciais. Apesar da utilização das TD pedagogicamente trazer demandas de diversos matises, os professores entendem a necessidade da utilização em sala de aula.

As participantes da pesquisa apresentaram postura de enfrentamento e superação dos desafios, utilizando as redes sociais, e a inclusão do softwares e certa medida, em suas atividades pedagógicas.

A inclusão das tecnologias para o ensino de Matemática é um processo que necessita da reflexão, aprendizado detalhado dos recursos e principalmente da mudança de postura de professores e estudantes, a criação de novo espaço educacional, e o investimento na aquisição de matérias adequados à demanda.

Apesar da insegurança na utilização do novo, das tecnologias de forma pedagógica, os professor foram unânimes em afirmar que tais recursos devem fazer parte da escola, visto que já fazem parte da vida dos estudantes.

Agradecimentos: Agradecemos aos membros do Grupo de Estudos em Educação Matemática (GEEM) e do Programa de Extensão "Ações Colaborativas e Cooperativas em Educação" (ACCE), pela colaboração no desenvolvimento da pesquisa.

\section{REFERÊNCIAS}

ALMEIDA, L. W.; SILVA, K. P.; VERTUAN, R. E. Modelagem matemática na educação básica. São Paulo: Contexto, 2012.

BORBA, M.; SILVA, R. S. R.; GADANIDIS, G. Fases das tecnologias digitais em educação matemática: sala de aula e internet em movimento. 1. ed. Belo Horizonte: Autêntica Editora, 2014.

BRITO, C. da S.; SANT'ANA, C. de C.; SANT'ANA, I. P. Memes com viés matemático e suas potencialidades para o ensino de Matemática. Revista Sergipana de Matemática e Educação Matemática, v. 5, n. 1, p. 173-188, 22 abr. 2020. D0l: 10.34179/revisem.v5i1.12019.

BRITO, C. da S.; SANT'ANA, C. de C.. Formação docente e jogos digitais no ensino de matemática. EDUCA - Revista Multidisciplinar em Educação, v. 7, n. 17, p. 415-434, 27 maio 2020. D0I: 10.26568/23592087.2020.4100. 
SOUSA, A. S.; SANT'ANA, C. de C. Formação de professores e histórias em quadrinhos na Educação Matemática: possibilidades e desafios. Revista Binacional Brasil-Argentina: diálogo entre as ciências, v. 6, n. 1, p. 137-152, 2017. D01: 10.22481/rbba.v6i1.1516.

CANNONE, G.; ROBAYNA, M. S.; MEDINA, M. M. P. 0 ensino da matemática e as novas Tecnologias da Informação e da Comunicação (TIC): estudo de caso de um grupo professores de ensino fundamental, Ciclo I, em Tenerife - Espanha. Zetetiké, Campinas, v. 16, n. 30, p. 107-138, 2008.

CECILIO, S.; ARAÚJO, D. O. S. Professores e tecnologias digitais no ensino superior: tendências de uso e implicações para a subjetividade de professores. Roteiro, Joaçaba, v. 38, n. 2, p. 337-364, 8 jul. 2013.

CIRINO, M. M.; SOUZA, A. R. Objetos de aprendizagem como ferramenta instrucional para professores de química no ensino médio. In: ENCONTRO NACIONAL DE PESQUISA EM EDUCAÇÃO EM CIÊNCIAS, 7., 2009, Florianópolis. Anais [...] Florianópolis: Universidade Federal de Santa Catarina, 2009.

COSTA, N. M. L. Reflexões sobre tecnologias e mediação pedagógica na formação do professor de matemática. In: BELINE, W.; COSTA, N. M. L. (org.). Educação matemática, tecnologias e formação de professores: algumas reflexões. Campo Mourão: Editora da FECLLCAM, 2010.

LEMOS, A.; LÉVY, P. 0 futuro da internet: em direção a uma ciberdemocracia planetária. São Paulo: Paulus, 2010.

LÉVY, P. As tecnologias da inteligência: o futuro do pensamento na era da informática. Rio de Janeiro: Editora 34, 1993.

LONGAREZI, A. M.; SILVA, J. L. Pesquisa-formação: um olhar para sua constituição conceitual e política. Revista Contraponto, Itajaí, v. 13, n. 3, p. 214-225, set./dez. 2013.

LOUREIRO, C. C.; GRIMM, V.; LUNARDI MENDES, G. M. "Imigrantes" versus "Nativos" digitais: o discurso de tecnologias digitais em políticas curriculares. Roteiro, Joaçaba, v. 41, n. 3, p. 725-742, 4 out. 2016. Disponível em: https://portalperiodicos.unoesc.edu.br/roteiro/article/view/10599. Acesso em: 5 abr. 2016.

MORAES, R.; GALIAZZI, M. C. Análise Textual Discursiva. 2. ed. rev. ljuí: Editora Unijuí, 2011.

NOVIKOFF, C; PEREIRA, N. X. Internet e ensino: saberes indispensáveis aos imigrantes digitais. In: SIMPÓSIO DE EXCELÊNCIA EM GESTÃO E TECNOLOGIA, 10., 2013, Rio de Janeiro. Anais [...] Rio de Janeiro: Associação Educacional Dom Bosco, 2013.

OKADA, A. L. P. Desafios para EAD: como fazer emergir a colaboração e a cooperação em ambientes virtuais de aprendizagem? In: SLVVA, M. (org.). Educação online: teorias, práticas, legislação, formação corporativa. São Paulo: Loyola, 2003.

PRENSKY, M. Nativos digitais imigrantes digitais. Tradução: Roberta de Moraes Jesus de Souza. Goiânia: Universidade Católica de Goiás, 2001. 
PURIFICAÇÃO, I. C.; NEVES, T. G.; BRITO, G. S. Professores de Matemática e as tecnologias: medo e sedução. In: BELINE, W.; COSTA, N. M. L. (org.). Educação matemática, tecnologias e formação de professores: algumas reflexões. Campo Mourão: Editora da FECLLCAM, 2010.

RAMALHO, B. L.; NUÑEZ, I. B.; GAUTHIIER, C. Formar o professor, profissionalizar o ensino: perspectivas e desafios. 2. ed. Porto Alegre: Editora Sulina, 2004.

RIBEIRO, E. S. 0 Software de Autoria Visual Class na formação continuada de professores: uma proposta para o ensino da Matemática nos anos iniciais. 2017. Dissertação (Mestrado em Educação Científica e Formação de professores) - Universidade Estadual do Sudoeste da Bahia, Jequié, 2017.

RIBEIRO, E. S.; SANTANA, I. P.; SANT'ANA, C. de C. Contribuições do software Visual Class nos conhecimentos da docência nos anos iniciais. Othar de Professor, v. 21, n. 2, p. 336-350, 2018. Disponível em: https://www.revistas2.uepg.br/index.php/olhardeprofessor/article/view/14195. Acesso em: 26 abr. 2020.

SANT'ANA, C. C.; AMARAL, R. B.; BORBA, M. C. 0 uso de softwares na prática profissional do professor de matemática. Revista Ciência \& Educação, v. 18, n. 3, p. 527-542, jul./set. 2012.

SERAFIM, M. L; SOUSA, R. P. Multimídia na educação: o vídeo digital integrado ao contexto escolar. In: SOUSA, R. P.; MOITA, F. M. G. S. C.; CARVALHO, A. B. G. (org.). Tecnologias digitais na educação. João Pessoa: EDUEPB, 2011.

SOUTO, D. L. P. Transformações expansivas na produção Matemática on-line. 1. ed. São Paulo: Cultura Acadêmica, 2014.

TARDIF, M.; LESSARD, C. 0 trabalho docente: elementos para uma teoria da docência como profissão de interações humanas. Tradução: João Batista Kreuch. 8. ed. Petrópolis: Vozes, 2013.

Endereço para correspondência: Rua M, n. 72, Pompílio Sampaio, 45206-145, Jequié, Bahia, Brasil; elysangelaribeiro@gmail.com 
